\title{
Design and Development of Material Handling Cum Transportation System
}

\author{
Eshan Deshpande ${ }^{1}$, Kshitij Bapat $^{2}$, Piyush Kedare ${ }^{3}$, Pratik Totalwar ${ }^{4}$, Raghav Dhoot $^{5}$, M. Sharique Tufail ${ }^{6}$ \\ Student, Department of Mechanical Engineering, YCCE, Nagpur, Maharashtra, India ${ }^{1,2,3,4,5}$ \\ Assistant Professor, Department of Mechanical Engineering, YCCE, Napur, Maharashtra, India ${ }^{6}$
}

\begin{abstract}
In today's fierce competitive global markets, customers are demanding adjustable sizes, higher quality, and flexibility: in short, they want it all. In order to stay competitive in the market, companies need to attain both customer satisfaction and cost reduction in production operations. Material Handling Systems (MHS) is the place to accomplish this goal, since they have a direct impact on production.
\end{abstract}

Keywords: Adjustable sizes, flexibility, customer satisfaction, cost reduction, production operations.

\section{INTRODUCTION}

Designing of lifting, pushing and pulling activities based on the physical and physiological capabilities of the operators is essential. The purpose of this study is to find a way to design and develop a material handling system (MHS) that works without affecting the routine of the operators, or the industry, while reducing the effort, time, and cost needed to transport materials through other means, while improving the overall work efficiency.

With this intention, we conducted a survey of the industrial grounds at KJV Alloy Conductors Pvt. Ltd. in Nagpur, India. During the study, we gathered information through various sources like interviews with the workers and the floor manager, observations and measurements. We found out that the main problem at the industry was related to the transport of cylindrical bobbins from the storage areas to a stranding machine and back. This process was done by mainly rolling the bobbins on the floor from storage to the machine, and vice versa. Further, we evaluated the gathered data under various criteria such as design elements, physical factors, and human need among others.

By analysing our findings from the study, we started to identify problems and challenges to be faced by such a material handling system from an industrial perspective. Thereafter we modified our design for the first time to accommodate industrial floors. Such changes would be done throughout our journey of designing an optimal Material Handling System.

To conclude, our research looked at the material handling and transport system design problems from an industrial point of view and solved them by adding human and management angles to design steps involved, thus developing a simple system capable of being driven by unskilled workers to lift and move heavy loads in short times, with minimum effort required by the worker.

\section{About The Industry:}

Name: KJV Alloy Conductors Pvt. Ltd.

Since 1989, this company has been manufacturing conductors including AAC - All Aluminium Conductor, ACSR - Aluminium Conductor Steel Reinforced, AAAC - All Aluminium Alloy Conductor, and ABC - Aerial Bunched Cable for Distribution \& Transmission power lines. They have supplied their products to major Electricity Boards and Turnkey Contractors of India as well as overseas.

Their products covers entire Range of voltage \& transmission lines suitable up to $765 \mathrm{kV}$. They have also successfully exported their products under stiff global competition. They have manufacturing units at Nagpur (Maharashtra) and Boregaon (Madhya Pradesh) with the annual production capacity of $24000 \mathrm{MT}$ PA. This industry is ISO 9001:2008 certified, and is located at Plot No. 31, Hingna MIDC Area, Central Service Road, Nagpur 440016. The industrial grounds are roughly $50 \times 45$ metres in area.

\section{What is an industrial Bobbin?}

A bobbin is a cylinder or cone holding wire, used especially in wire drawing industries. The bobbins that we worked with at KJV Alloys Pvt. Ltd. are shown in Fig. 1:

\section{OBJECTIVES}

The objectives of our research are listed as follows:

To alleviate the efforts required by workers to transport bobbins

To reduce time required in the completion of a work cycle in an industry.

To reduce the costs associated with a work cycle at an industry.

To improve the work efficiency of the industrial grounds. 


\section{LITERATURE REVIEW}

We relied upon the following research understand the scope of our research:

Design and Fabrication of Drum Handling Equipment - A shown in Fig. 1).

Review, by Nilesh K. Garghate, KDKCE, Nagpur.

Modelling and Design of a Direct Drive Lift Control with Rope Elasticity, by S. Bolognani, University of Padova, Italy.

Torque Balanced Wire Rope, by W. Lucht And F. people to work. Doneckar, SAE Technical Paper.

\section{PROBLEM IDENTIFICATION}

The following problems were faced by us during the research for our project:

There is a lot of man power and time that goes into transportation of industrial bobbins weighing from $50 \mathrm{~kg}$ up to $200 \mathrm{~kg}$ gross. (See Fig. 1)

Industrial grounds are not spacious enough to accommodate conventional transportation systems like crane carriers or trucks.

Other transportation systems (like gantry cranes) use too much power and hence can not be used multiple times throughout the day, especially not for transportation of relatively smaller items.

New innovations to tackle such problems may require skilled personnel for operation, and training workers to operate such a machine would take a lot of time and money.

Solutions may also require the industry to modify their layout to accommodate the solution, which would cost a lot of money and time for the industry.

Bobbins are to be transported to a stranding machine. This machine needs $4-5$ bobbins at a time. Transporting bobbins manually, one at a time is a very slow process.

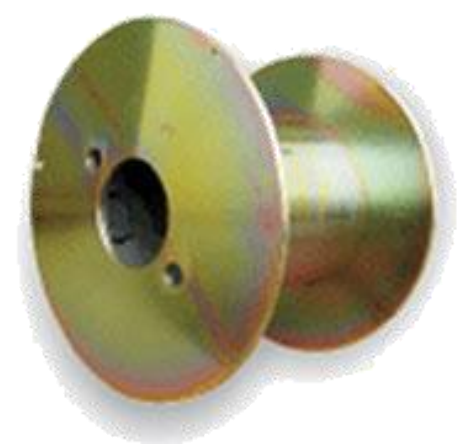

Fig. 1 Industrial Bobbin
The current method of transporting bobbins includes passing a metallic rod through this hole, after which two workers lift the rod from either end, and transport the bobbin from the pick-up spot to the stranding machine. This, as we know, takes a lot of time. It also requires 2

\section{Proposed Solutions:}

- $\quad$ One of the proposed solutions is to manually roll the bobbins from the pick up spot to the stranding machine as rolling doesn't require as much exertion as lifting does. However this solution fails to take into account the unevenness of the shop floors. It also doesn't consider the fact that there is still only one bobbin being transported at a time.

- The second proposed solution is to lift $4-5$ bobbins together using a hydraulic lift mechanism. This solution also fails to factor in the high cost of a piston cylinder mechanism to lift a weight of around $700 \mathrm{~kg}$. Such a hydraulic lift would cost a lot more than the industry is willing to spend on it. It would also require periodic lubrication, and would provide a very limited bending ability.

- Another proposed solution is to use a transportation system with a chain hoist mechanism instead of a wire rope hoist mechanism. The problem with this solution is that a chain hoist requires more accurate mounting whereas a rope hoist mechanism doesn't.

Also, a chain hoist mechanism may show velocity fluctuations and generate heat in heavy cycles, which is not a problem with a rope hoist mechanism.

\section{Our Solution:}

We propose a solution that involves lifting of multiple bobbins using a wire rope hoist mechanism. This project is completely human driven and doesn't require any skilled training to operate. It is a very compact design, and thus, would no pose a problem to industries with limited moving space.

The project doesn't require any electricity or fuel to operate, hence saving a lot of money. It also consists of a palette to drop the bobbins on after lifting, so the wire rope hoist does not endure stress throughout the process of transporting the bobbins. This project needs only one worker to operate it, hence saving manpower. 


\section{IJARCCE}

\section{EXPERIMENTATION}
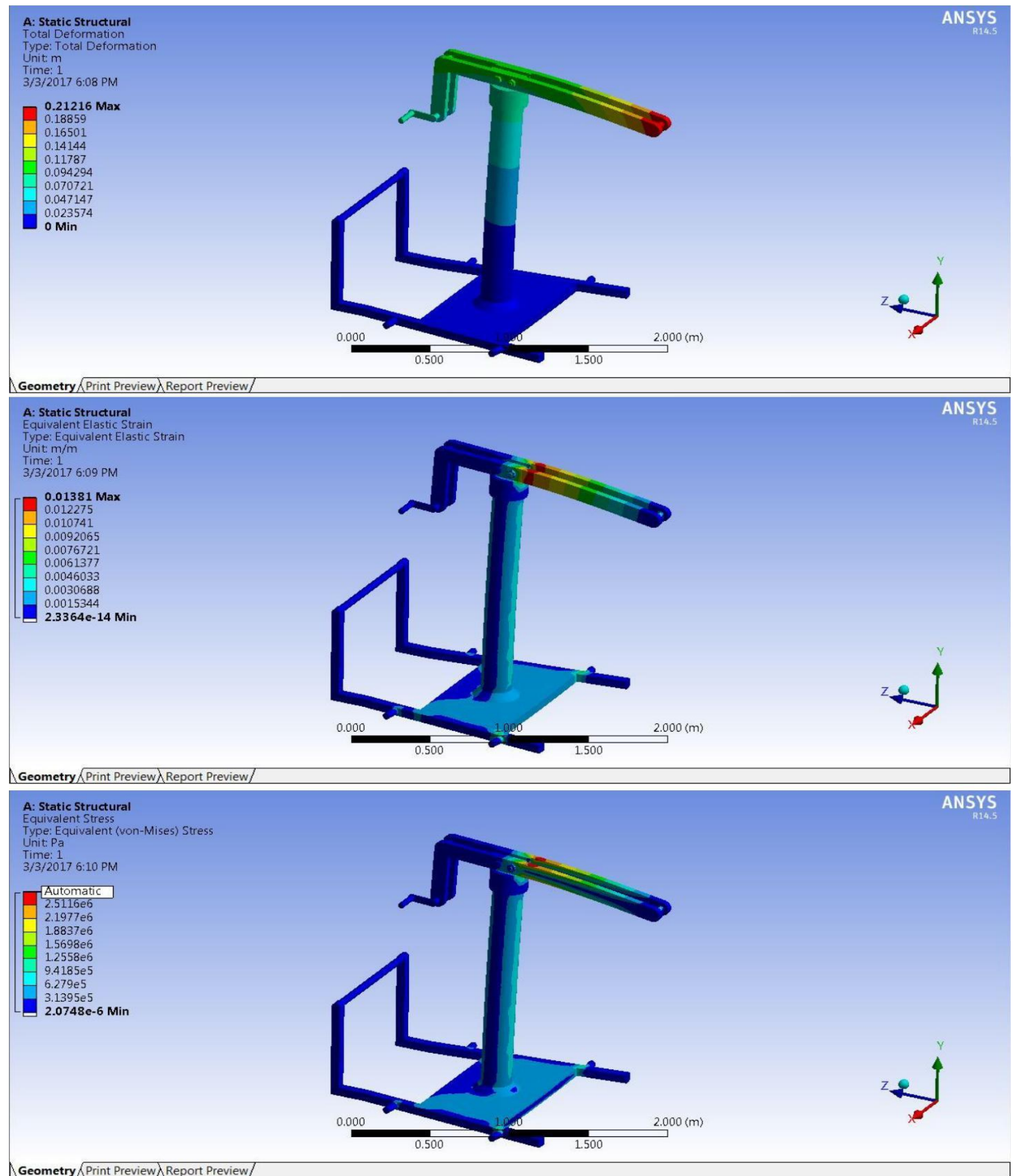

\section{RESULTS}

After thorough calculations and simulative experimentation, we found out that the critical stress for our design would be around $460 \mathrm{MPa}$, while the maximum stress that is put on the design at any point for a weight of $350 \mathrm{~kg}$ doesn't exceed $3 \mathrm{MPa}$ at any point during the simulation. Our design is hence safe.
[2] Modelling and Design of a Direct Drive Lift Control with Rope Elasticity, by S. Bolognani, University of Padova, Italy.

[3] Torque Balanced Wire Rope, by W. Lucht And F. Doneckar, SAE Technical Paper

[4] www.wikipedia.org

[5] www.asmedigitalcollection.asme.org www.google.co.in

[6] Ergonomic Design for Material Handling Systems by K.H.E. Kroemer Material Handling Systems Design by James MacGregor Apple

\section{REFERENCES}

[1] Design and Fabrication of Drum Handling Equipment - A Review, by Nilesh K. Garghate, KDKCE, Nagpur. 